\title{
クラス不均衡データに対する ミシガン型ファジィ遺伝的機械学習†
}

\author{
西原 光洋*1 - 増山 直輝 $* 1$ - 能島 裕介*1 - 石㴊 久生 $* 2$
}

近年, 医療や金融など識別結果に対する根拠が求められる分野において, 識別器の解釈可能性が盛んに議論されている. ファジィ遺伝的機械学習は, 解釈性に優れた識別器を設計する手法の一つである。一方で, クラス不均衡なデー夕におい て, 少数派クラスの高い識別性能が要求される場合がある。このとき, ファジイ遺伝的機械学習により生成される識別器 は, 少数派クラスの識別性能が他クラスより低下する. 本研究では, 少数派クラスの識別性能を向上させるために, ファ ジィ遺伝的機械学習に対して 4 つの変更を行う。1)ルールの評価関数にクラス毎のパターン数による重み付け, 2)ルール 集合の評価にクラス毎の識別精度の調和平均を利用，3) ヒューリスティックルール生成のベースパターンをクラス毎の識 別精度を基に選択, 4) ルール後件部にクラス間のパターン比率による重み付け. 数值実験では, 各変更が識別性能に与え る影響を調査し有効性を示す。

キーワード : ファジィ識別器, 遺伝的機械学習, 不均衡データセット

\section{1.はじめに}

近年の情報技術の発展により，AI を必要とする夕スクの多 様化が促進され，これに伴い識別器に対して単純な識別精度以 外の性能を要求される場面が増加している，特に医療・金融な どの業務に対する信頼性や確実性が重要視される分野におい ては, 識別器の透明性, すなわち識別器の解釈性能が求められ る [1]. ファジィ識別器はファジィ If-then ルールの集合で構成 される識別器であり, 識別結果を言語的に解釈可能であること から, 高い解釈性能を有する. ファジィ遺伝的機械学習 (Fuzzy Genetics-based Machine Learning : FGBML) [2]は，遺伝的ア ルゴリズムを用いることにより少ない計算資源でファジイ識別 器を生成する手法である.

学習に悪影響を与えるデータセットの一つとして, 各クラス のパターン数に多寡が存在する不均衡データセットが存在す る。実世界における不均衡データセットを取り扱う多くのタス クでは, 少数派クラスの識別性能が多数派クラスより重要視さ れる。一例として医療分野では, 疾患の陽性クラスに対する識 別精度を陰性クラスよりも重要視する一方, 陽性クラスのサン プルは陰性より獲得が困難な場合が多い。このとき, FGBML は全サンプルの識別精度を最大化するよう学習を進めるため, 得られる識別器は多数派クラスである陰性クラスに対して高い 識別性能を示す一方, 少数派クラスである陽性クラスの識別性 能が十分に確保されない. したがって, 不均衡データセットを

\footnotetext{
$\dagger \quad$ Michigan-Style Fuzzy Genetics-Based Machine Learning for Class Imbalance Data

Akihiro NISHIHARA, Naoki MASUYAMA, Yusuke NOJIMA, and Hisao ISHIBUCHI

* 1 大阪府立大学

Osaka Prefecture University

*2 南方科技大学

Southern University of Science and Technology
}

取り扱うためにFGBML を拡張することが必要である。

本研究では Michigan 型 FGBML [2] に対して, 不均衡データ セットの取り扱いを考慮した改良を行う. 提案手法では, ファ ジィルールの後件部および評価值の算出において, データセッ トの不均衡率を重みとして用いる。また，ルール生成に用いる パターンをクラス毎の誤識別率に基づいて抽出する.ささら， ルール集合の評価に各クラスの識別精度の調和平均を用いる。

本論文は以下のように構成される．2 章で本研究のベースと なる Michigan 型FGBML について述べ，3 章で提案手法を説 明する，4 章で数值実験を通じて，提案手法による各变更が FGBML に与える影響を調査し, 提案手法の不均衡データセッ トに対する有効性を示す，最後に 5 章で本論文をまとめる.

\section{Michigan 型ファジィ遺伝的機械学習}

FGBML には，1つのルールを 1 個体として表現する Michigan 型と 1 つのルール集合を 1 個体として表現する Pittsburgh 型が存在する。本研究では計算コストを削減するために, Michigan 型の FGBML を用い, 各個体はファジィルールの 前件部であるメンバシップ関数の組合せをコード化して保持す る.ファジィルールの後件部は, 学習用データに対する前件部 適合度により自動的に設定される [2]. Michigan 型 FGBML で は, Algorithm 1 に従って識別器の獲得が行われる.

\section{1 ファジィルールの構成}

$n$ 次元 $M$ クラスのパターンを持つ $m$ 個の学習用パターン $\mathbf{x}_{p}=\left(x_{p 1}, \ldots, x_{p n}\right)$ が与えられているパターン識別問題を考え る.この問題に対するファジィ識別器では, $q$ 番目のファジィ ルール $R_{q}$ は以下に示される If-then 形式で生成する.

Rule $R_{q}$ : If $x_{p 1}$ is $A_{q 1}$ and $\ldots$ and $x_{p n}$ is $A_{q n}$ then Class $C_{q}$ with $C F_{q}$ 

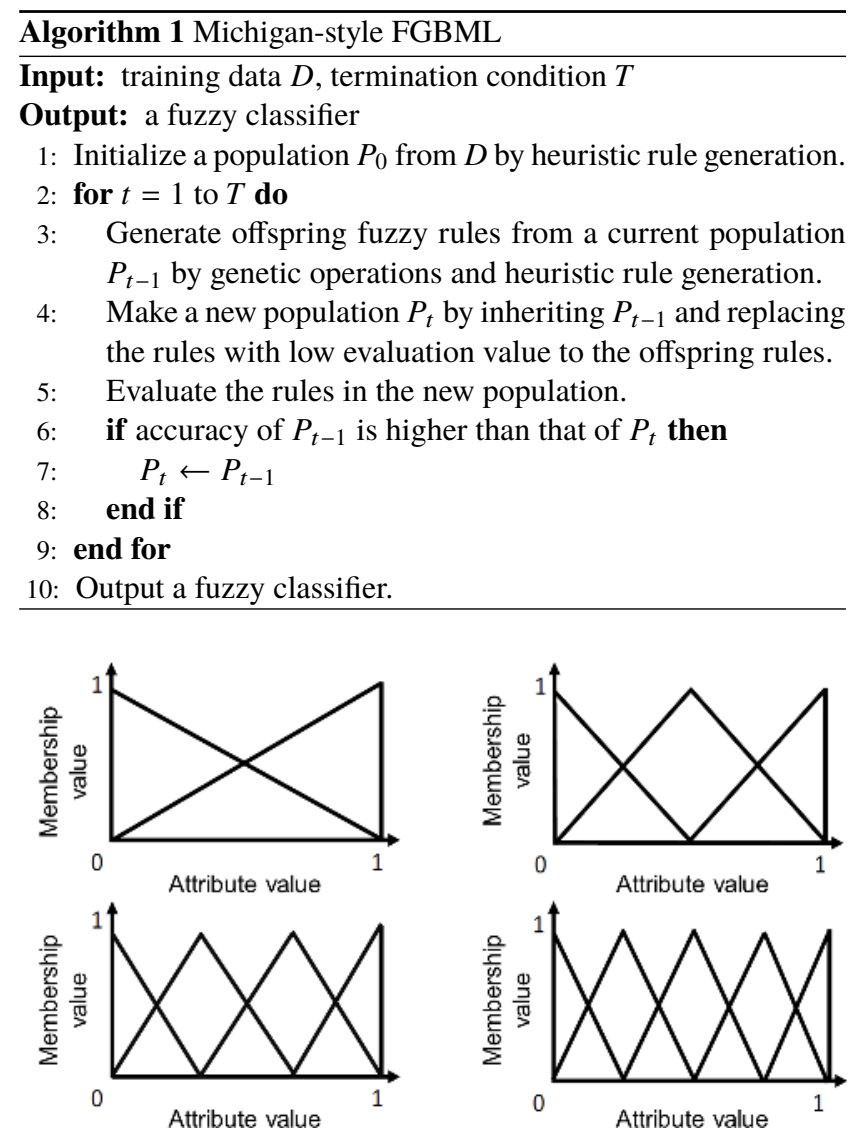

図 1 三角型メンバシップ関数

する前件部, $C_{q}$ は結論部クラス, $C F_{q}$ はルールの重みを表す. ファジィ集合には，計算が容易かつ一般に広く用いられている 三角型メンバシップ関数を用いる. 各ファジィ集合は図 1 に示 す 2 分割から 5 分割までのメンバシップ関数によって定義さ れる。また，ルールの汎化性を高めるために，任意の属性值に 対してメンバシップ值が常に 1 である “don't care”も条件部 集合として用いる。

\section{2 初期個体群の生成}

初期個体群の生成では, Algorithm 2 に示す複数のパターン よりルールを生成するヒューリスティック生成法 [3] 用い る。本研究ではベースパターンの近傍パターンをサポートパ ターンとして選択する．これにより，ベースパターンが少数派 クラスである場合, 周囲の少数派クラスのサポートパターンを 覆うルールの獲得が期待される.

\section{3 ルールの評価}

各パターンの識別には単一勝利ルールによる推論法 [4] を用 いる，そのため, 各パターンにつき一つの勝利ルールが決定さ れる. ルール $R_{q}$ の評価関数 $f\left(R_{q}\right)$ は以下のように表される.

$$
f\left(R_{q}\right)=N C P\left(R_{q}\right)-N M P\left(R_{q}\right)
$$

ここで, $N C P\left(R_{q}\right)$ および $N M P\left(R_{q}\right)$ はそれぞれ, ルール $R_{q}$ が 正しく識別および誤識別したパターン数である.

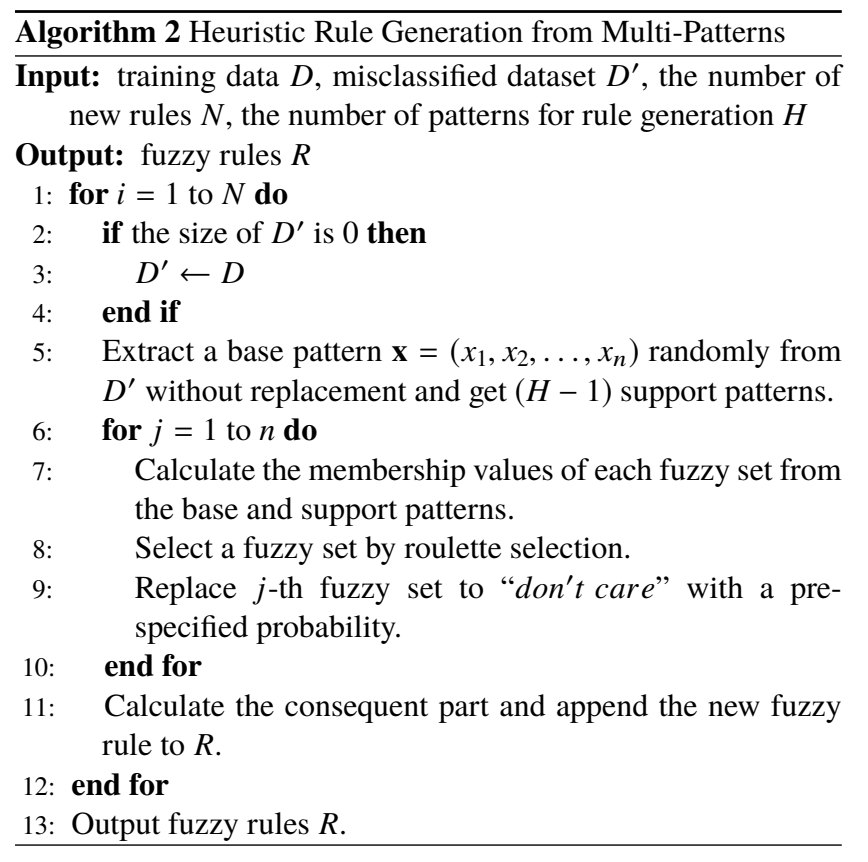

\section{4 新規ルールおよび新規個体群の生成}

新規ルールの生成には, 遺伝的生成法とヒューリスティック 生成法の 2 種類の方法を用いる. 遺伝的生成法では, ランダム に選択された $2 つ の$ 親個体から交叉および突然変異を通じて, 新規ルールを生成する. ヒューリスティック生成法では, 現個 体群が誤識別したパターン, あるいは識別不能としたパターン をベースパターンに用いて新規ルールを生成する。この際, 新 規ルールの生成は初期個体群の生成と同様に行われる.

既定数の新規ルールを生成した後に, 現個体群から新規個体 群を生成する。これは Algorithm 1 の Line 4 の通りに実行さ れる. 新規個体の生成数を $N_{\text {new }}$ とするとき, 現個体群を評価 值とともに新規個体群として引き継いだ後に, 新規個体群にお ける評価值が最下位から $N_{\text {new }}$ 番目までのルールを新規ルール と置換する

\section{5 個体群の更新および識別器の獲得}

個体群の更新では, 現個体群と 2.4 節で生成した新規個体群 を比較し, 学習用パターンに対する識別精度が高い方を次世代 の現個体群とする [5]. これにより最終世代において, 学習用 パターンに対する最良の識別精度を示す個体群を識別器として 獲得できる。

\section{3. 提案手法}

本研究において提案する改良は, 不均衡なマルチクラスデー タセットについても対応可能である. なお本論文では, 議論を 簡潔にするため, 2 クラスの不均衡データセットを取り扱う.

\section{1 ルール評価関数に対する重みづけ}

不均衡データセットを学習に用いる際に式 (2) をルール評価 関数とすると, クラス間のパターン数の多寡から, 多数派クラ スを識別するルールの評価值が高くなる傾向にある. 提案手法 では, 各ルールに対する評価值として, 式 (2)におけるパター 
ンの識別数および誤識別数に対してクラス間のパターン数の 比率に応じた重みを与える。すなわち, ルール $R_{q}$ の評価関数 $f\left(R_{q}\right)$ は以下のように定義される

$$
f\left(R_{q}\right)=\frac{N C P\left(R_{q}\right)}{m_{C_{q}}}-\sum_{h \neq C_{q}} \frac{N M P\left(R_{q}, h\right)}{m_{h}}
$$

ここで, $h$ は用いたクラス番号, $N M P\left(R_{q}, h\right)$ はルール $R_{q}$ が 誤識別したクラスのパターン数を表す。また, $m_{h}$ はクラス $h$ のパターン数である.

式 (3)により, 少数派クラスを結論部に持つルールは, 少数 のパターンを正しく識別するだけで大きな評価值が与えられ, 多数派クラスのパターンの誤識別によるペナルティも小さくな り，結果として次世代に保存されやすくなる.

\section{2 ルール集合の評価指標}

2.5 節のように学習用パターン全体に対する識別精度をルー ル集合の評価指標に設定する場合，不均衡データセットを学習 に用いると, クラス間のパターン数の多寡から, 多数派クラス の識別性能がルール集合の評価に大きな影響を与える。した がって，少数派クラスおよび多数派クラスの識別性能を同時に 考慮した評価指標を用いる必要がある。本論文では，各クラス の識別精度の調和平均をルール集合の評価指標に用いる。

\section{3ヒヒーリスティック生成法のベースパターン選択}

ヒューリスティック生成法では Algorithm 2 の Line 4 の通 り，誤識別パターンからベースパターンをランダムに選択す る. 不均衡データセットを学習に用いる場合, 誤識別パターン の集合においても学習用データセットの不均衡度が反映される ため, 多数派クラスのパターンがベースパターンに選択されや すくなる。ヒューリスティック生成法で生成されるルールは ベースパターンのクラスを支持する場合が多く，結果的に多数 派クラスのルールが多く生成される。したがって，データセッ 卜の不均衡度を考慮したベースパターンの選択が必要である。

提案手法では, 各世代においてクラス $h$ の誤識別パターンが 選択される確率 $P(h)$ を以下のように定める.

$$
\begin{aligned}
& P(h)=\frac{q_{h}}{\sum_{s=1}^{M} q_{s}} \\
& q_{s}=\frac{N M P(s)-m_{s, \text { used }}}{m_{s}}
\end{aligned}
$$

ここで, 式(5)の NMP $(s), m_{s}, m_{s, \text { used }}$ はそれぞれクラス $s$ の 誤識別したパターン数, 総パターン数, ヒューリスティック生 成に用いられたパターン数を表す。各世代においてヒューリス ティック生成法により 1 つ目のルールを生成する時, $q_{s}$ は各 クラスの誤識別率と等しい. その後, パターンが選択されるご とに $P(h)$ の值が更新される。これにより，前世代における各 クラスの識別率，および現世代におけるべースパターン選択の 状況に応じて, 次のベースパターンが選択される。 なお, 全て の誤識別パターンが選択された場合, Algorithm 2 の Line 3 と 同様に全てのパターンを選択可能とする。このとき, 式 (5)に おいて $N M P(s)=m_{s}$, および $m_{s, u s e d}=0$ と代入する.

\section{4 ルール後件部の設定}

ファジィルールの前件部 $\mathbf{A}_{q}$ の後件部クラス $h$ に対する信頼 度 $c\left(\mathbf{A}_{q} \Rightarrow\right.$ Class $\left.h\right)$ は，以下の式 (6), (7) で計算される.

$$
\begin{aligned}
& \mu_{\mathbf{A}_{q}}\left(\mathbf{x}_{p}\right)=\prod_{i=1}^{n} \mu_{A_{q i}}\left(x_{p i}\right) \\
& c\left(\mathbf{A}_{q} \Rightarrow \text { Class } h\right)=\frac{\sum_{\mathbf{x}_{p} \in \operatorname{Class} h}^{m} \mu_{\mathbf{A}_{q}}\left(\mathbf{x}_{p}\right)}{\sum_{p=1}^{m} \mu_{\mathbf{A}_{q}}\left(\mathbf{x}_{p}\right)}
\end{aligned}
$$

ここで $\mu_{A_{q i}}\left(x_{p i}\right)$ は属性值 $x_{p i}$ のメンバシップ関数 $A_{q i}$ に対す るメンバシップ值, および $\mu_{\mathbf{A}_{q}}\left(\mathbf{x}_{p}\right)$ はパターン $\mathbf{x}_{p}$ の $\mathbf{A}_{q}$ に対 する適合度を表す。適合度総和を最大化するクラスが, 前件部 $\mathbf{A}_{q}$ に対する結論部クラスとして獲得される。 しかし, 式 (7) は各クラスのパターン数に依存しているため, 少数派クラスの 信頼度は低くなり, 少数派クラスの新規ルールが獲得困難にな る. 提案手法では, 各クラスのパターン数に依存しないルール の信頼度を獲得するため, クラス $h$ に対する信頼度を以下の式 (8) で再定義する.

$$
\begin{aligned}
& c\left(\mathbf{A}_{q} \Rightarrow \text { Class } h\right)=\frac{\sum_{\mathbf{x}_{p} \in \operatorname{Class} h}^{m} \alpha_{p} \cdot \mu_{\mathbf{A}_{q}}\left(\mathbf{x}_{p}\right)}{\sum_{p=1}^{m} \alpha_{p} \cdot \mu_{\mathbf{A}_{q}}\left(\mathbf{x}_{p}\right)} \\
& \alpha_{p}=\frac{m_{\text {major }}}{m_{C_{\mathbf{x}_{p}}}}
\end{aligned}
$$

ここで，式 (9)において $m_{\text {major }}$ および $m_{C_{\mathbf{x}_{p}}}$ はそれぞれ，多 数派クラスのパターン数および $\mathbf{x}_{p}$ のクラスのパターン数であ る. $\alpha_{p}$ は $\mathbf{x}_{p}$ のクラスのパターン数が少ないほど大きくなる.

\section{4. 数值実験}

数值実験では, 従来の FGBML, 代表的なオーバーサンプ リング手法である SMOTE [6] を適用した FGBML に対して, 提案手法における 4 つの変更点の各種 1 つのみを適用した FGBML, および提案手法で識別器を生成し, 識別性能の比較 を行う。これにより, 各種変更点がFGBMLに与える影響, お よび提案手法の不均衡データセットに対する有効性を調査す る. なお, 今回の実験では識別性能として, 多数派クラスおよ び少数派クラスの識別精度の算術平均である AUC を用いる.

\section{1 データセット}

数值実験では, KEEL-data set repository [7] より提供され ている複数の不均衡な 2 クラスのデータセットを用いる. 表 1 は今回の実験に用いたデータセットである。表 1 における Ba:mi1 以下のデータセットは, マルチクラスのデータセット を 2 クラスに変換した疑似 2 クラスデータセットである。 コ ロン前の 2 文字は元のデータセットから取っており, それぞ れ $\mathrm{Ba}=\mathrm{Bal}, \mathrm{Ec}=$ Ecoli, $\mathrm{Gl}=$ Glass, $\mathrm{Ne}=$ Newthyroid, $\mathrm{PB}=$ Page-blocks, Ve = Vehicle, Vo = Vowel, Ye = Yeast を表す．コ ロン後の記述について, “mi”は少数派クラス, “ma”は多数派 クラスとする元クラスを表す。一例として, “Ba:mi1”は Bal 
表 1 データセット

\begin{tabular}{crrrr}
\hline 名前 & パターン数 & 属性数 & $f_{\max }$ & \multicolumn{1}{c}{ IR } \\
\hline Haberman & 306 & 3 & 0.06 & 2.78 \\
Spectfheart & 267 & 44 & 0.55 & 3.85 \\
Appendicitis & 106 & 7 & 0.81 & 4.05 \\
Ba:mi1 & 625 & 4 & 0.00 & 11.82 \\
Ec:mi5 & 336 & 7 & 1.20 & 15.67 \\
Gl:mi2 & 214 & 9 & 0.39 & 11.66 \\
Ne:mi0 & 215 & 5 & 2.50 & 6.14 \\
PB:ma0 & 5,472 & 10 & 0.51 & 8.80 \\
PB:mi4 & 5,472 & 10 & 2.05 & 194.43 \\
Ve:mi0 & 846 & 18 & 1.12 & 3.25 \\
Ve:mi1 & 846 & 18 & 0.17 & 2.90 \\
Vo:mi0 & 990 & 13 & 2.46 & 10.00 \\
Vo:mi9 & 990 & 13 & 2.46 & 10.00 \\
Vo:mi10 & 990 & 13 & 0.03 & 10.00 \\
Ye:mi3 & 1,484 & 8 & 4.20 & 32.33 \\
Ye:mi4 & 1,484 & 8 & 1.25 & 28.41 \\
Ye:mi7 & 1,484 & 8 & 0.14 & 49.00 \\
Ye:mi8 & 1,484 & 8 & 1.13 & 75.92 \\
\hline
\end{tabular}

表 2 実験設定

\begin{tabular}{cc}
\hline パラメータ & 值 \\
\hline 試行回数 & $20(10 \mathrm{CV} \times 2)$ \\
終了世代 & 10,000 \\
交叉確率 & 0.9 \\
突然変異確率 & $1 / n(n:$ 属性数 $)$ \\
“don't care”適用確率 & $(n-5) / n$ \\
個体群サイズ & 100 \\
新規個体生成数 & 20 \\
近傍個体群サイズ $(\mathrm{SMOTE)}$ & 5 \\
サポートパターン数 & 5 \\
\hline
\end{tabular}

データセットのクラス 1 を少数派クラスとし, それ以外のクラ スを多数派クラスとした 2 クラスデータセットを表す。表 1 に おいて， $f_{\max }$ は，2クラスのデータセットにおける属性值の重 なり度合いを示す指標であり, 以下の式 (10) で求められる [8].

$$
f_{\max }=\max _{i}\left\{\frac{\left(\mu_{i 1}-\mu_{i 2}\right)^{2}}{\sigma_{i 1}^{2}+\sigma_{i 2}^{2}}\right\}
$$

ここで $\mu_{i 1} \cdot \mu_{i 2} \cdot \sigma_{i 1}^{2} \cdot \sigma_{i 2}^{2}$ はそれぞれ, 各クラスにおける $i$ 番 目の属性值の平均および分散を表す。識別問題では，ある属性 においてクラス間のパターン分布の重なり度合いが小さけれ ば，その属性により識別が容易となる。式 (10)より， $f_{\max }$ が 小さいデータセットほど, クラス間のパターン分布の重なり度 合いが大きい. また，表 1 の IR (Imbalanced Rate）は少数派 クラスのパターン数を 1 としたときの多数派クラスのパターン 数の比率であり, IR が大きいデータセットほど 2 クラス間の パターン数の比率に偏りがある。その他の実験設定は表 2 に 示す.
表 $3 \mathrm{AUC}$ の平均值

\begin{tabular}{crrrrrrr}
\hline$D S$ & BASE & SMOTE & RU-F & RS-F & HEU & CON & PRO \\
\hline Haber & 0.50 & 0.61 & 0.50 & 0.50 & 0.50 & 0.57 & $\mathbf{0 . 6 2}$ \\
Spectf & 0.50 & $\mathbf{0 . 7 7}$ & 0.50 & 0.50 & 0.50 & 0.59 & 0.74 \\
Append & 0.56 & $\mathbf{0 . 7 5}$ & 0.50 & 0.56 & 0.50 & 0.72 & 0.74 \\
Ba:mi1 & 0.50 & 0.51 & 0.50 & 0.50 & 0.50 & $\mathbf{0 . 6 0}$ & 0.54 \\
Ec:mi5 & 0.50 & 0.83 & 0.50 & 0.50 & 0.50 & 0.69 & $\mathbf{0 . 8 7}$ \\
Gl:mi2 & 0.50 & 0.50 & 0.50 & 0.50 & 0.50 & 0.62 & $\mathbf{0 . 6 5}$ \\
Ne:mi0 & 0.68 & 0.77 & 0.50 & 0.68 & 0.50 & 0.89 & $\mathbf{0 . 9 8}$ \\
PB:ma0 & 0.54 & 0.59 & 0.50 & 0.54 & 0.50 & 0.54 & $\mathbf{0 . 8 7}$ \\
PB:mi4 & 0.50 & 0.57 & 0.59 & 0.76 & 0.50 & 0.57 & $\mathbf{0 . 9 0}$ \\
Ve:mi0 & 0.51 & 0.61 & 0.50 & 0.51 & 0.50 & 0.66 & $\mathbf{0 . 9 1}$ \\
Ve:mi1 & 0.51 & 0.66 & 0.50 & 0.51 & 0.50 & 0.65 & $\mathbf{0 . 6 9}$ \\
Vo:mi0 & 0.64 & 0.53 & 0.55 & 0.86 & 0.52 & 0.59 & $\mathbf{0 . 9 2}$ \\
Vo:mi9 & 0.68 & 0.53 & 0.51 & 0.80 & 0.50 & 0.58 & $\mathbf{0 . 9 0}$ \\
Vo:mi10 & 0.50 & 0.56 & 0.50 & 0.51 & 0.50 & 0.57 & $\mathbf{0 . 7 7}$ \\
Ye:mi3 & 0.50 & 0.72 & 0.50 & 0.50 & 0.50 & 0.74 & $\mathbf{0 . 9 5}$ \\
Ye:mi4 & 0.50 & 0.70 & 0.50 & 0.50 & 0.50 & 0.55 & $\mathbf{0 . 8 1}$ \\
Ye:mi7 & 0.50 & 0.53 & 0.50 & 0.50 & 0.50 & 0.55 & $\mathbf{0 . 6 1}$ \\
Ye:mi8 & 0.51 & 0.61 & 0.50 & 0.51 & 0.50 & 0.50 & $\mathbf{0 . 7 1}$ \\
\hline
\end{tabular}

\section{2 実験結果および考察}

実験結果を表 3 に示す。表 3 で, Haberman, Spectfheart, Appendicitisの名前は省略して示す。また, BASEは従来の FGBML, RU-F は 3.1 節のルールの評価関数の重みづけ, RS-F は 3.2 節のルール集合の評価関数変更, HEU は 3.3 節のヒュー リスティック生成法のベースパターン選択, CON は 3.4 節の ルール後件部の設定のそれぞれのみを適用した FGBML，およ びPRO は提案手法を表す.太字は各データセットにおける最 良の結果を示す．また, Wilcoxon の順位和検定（有意水準 5\%) を行い, 提案手法より有意差ありで劣る結果は青, 有意差あり で優れる結果は赤, 有意差が無い結果は黒で示す、

表 3 より, 多くのデータセットについて提案手法が有意差の ある最良值を示したことから，提案手法は FGBML を不均衡 データセットに対応できるよう拡張したと言える，特に，提案 手法はSMOTE に対しても優位であることが分かる，

各変更点を分析すると, CON が他の変更を適用した場合と 比較して, 多くのデータセットにおいて識別性能を大きく改善 させている. また, RS-F はオーバーラップの弱い複数のデー タセットにおいてのみ識別性能を改善させているが, RU-F お よび HEU ではほぼ全てのデータセットにおいて識別性能が低 下している。 これらの事から，ルール評価関数，ルール集合の 評価関数, およびベースパターン選択に対する変更は, それ単 体では有効性がそしいことが分かる。これらの変更が有効に働 くためには, 個々の If-then ルールの生成時から不均衡デー夕 に対応した調整を加えることが必要であると推測される.

\section{5. 終わりに}

本研究では Michigan 型 FGBML に対して, 不均衡な 2 クラ スデータセットを取り扱うための拡張手法を提案した。数值 
実験より提案手法では，ルール評価関数，ルール集合の評価指 標, ヒューリスティック生成法, およびルール後件部の調整を 行うことにより，不均衡データセットに対しても適用可能な FGBML を実現した，今後の課題は，既存の FGBML の改良を 提案手法に適用することによる解釈性能を保持した識別性能の 向上が挙げられる。

\section{謝辞}

本研究は, 本研究は科研費 - 基盤研究 C (19K12159) の助成 を受けたものである.

\section{参 考 文 献}

[1] A. Adadi and M. Berrada: "Peeking Inside the Black-Box: A Survey on Explainable Artificial Intelligence (XAI)," IEEE Access, Vol.6, pp. 52138-52160, 2018.

[2] H. Ishibuchi and T. Nakashima: "Improving the performance of fuzzy classifier systems for pattern classification problems with continuous attributes," IEEE Trans. on Industrial Electronics, Vol.46, No.6, pp. 1057-1068, 1999.

[3] Y. Nojima, K. Watanabe, and H. Ishibuchi: "Variants of heuristic rule generation from multiple patterns in Michigan-style fuzzy genetics-based machine learning," Proc. of the Conf. on Technologies and Applications of Artificial Intelligence (TAAI 2015), Nov. 20-22, Tainan, pp. 427-432, 2015.

[4] H. Ishibuchi, T. Nakashima, and T. Morisawa: "Voting in fuzzy rule-based systems for pattern classification problems," Fuzzy Sets and Systems, Vol.103, No.2, pp. 223-238, 1999.

[5] Y. Nojima, S. Takemura, K. Watanabe, and H. Ishibuchi: "Michigan-style fuzzy GBML with $(1+1)$-ES generation update and multi-pattern rule generation," Proc. of Joint 17th World Congress of Int. Fuzzy Systems Association and 9th Int. Conf. on Soft Computing and Intelligent Systems (IFSA-SCIS 2017), Jun. 27-30, Otsu, pp. 1-6, 2017.

[6] N. V. Chawla, K. W. Bowyer, L. O. Hall, and W. P. Kegelmeyer: "SMOTE: Synthetic minority over-sampling technique," J. of Artificial Intelligence Research, Vol.16, pp. 321-357, 2002.

[7] KEEL: "A software tool to assess evolutionary algorithms for Data Mining problems (regression, classification, clustering, pattern mining and so on)," https://sci2s.ugr.es/keel/datasets.php [accessed Aug. 13, 2019]

[8] S. Alshomrani, A. Bawakid, S. O. Shim, A. Fernández, and F. Herrera: "A proposal for evolutionary fuzzy systems using feature weighting: Dealing with overlapping in imbalanced datasets," Knowledge-Based Systems, Vol.73, pp. 1-17, 2015.

(2020 年 10 月 5 日 受付)

(2020 年 10 月 23 日 採録)
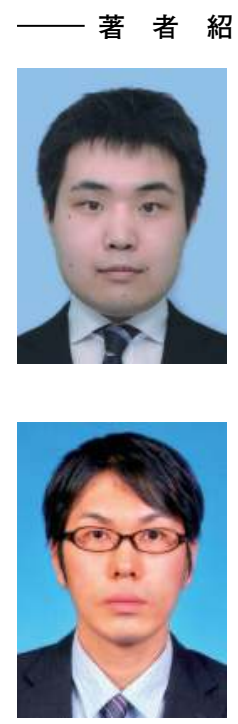

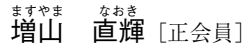

2010 年日本大学理工学部航空宇宙工学科卒 業. 2012 年首都大学東京システムデザイン研 究科ヒューマンメカトロニクスシステム学域 (現：知能機械システム工学域）博士前期課 程修了. 2016 年マレーシア国マラヤ大学計算 機科学 - 情報技術学部人工知能学科博士後期 課程修了. 博士 (工学) . 2016 年マラヤ大学 計算機科学 - 情報科学部博士研究員. 2017 年 より大阪府立大学工学研究科電気 - 情報系専 攻知能情報工学分野助教, 現在に至る. 主に データマイニングや教師なし学習の研究に従 事. IEEE, 日本知能情報ファジィ学会の会員.

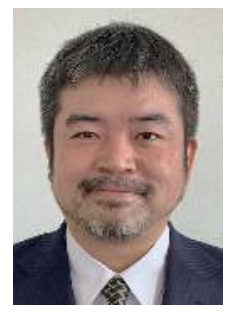

\section{能島籍奟 [正会員]}

1999 年大阪工業大学工学部機械工学科卒業. 2001 年同大学大学院工学研究科博士前期課 程機械工学専攻修了. 2004 年神戸大学大学院 自然科学研究科博士後期課程システム機能科 学専攻修了. 同年大阪府立大学大学院工学研 究科助手, 2007 年同助教, 2013 年同准教授, 2020 年同教授, 現在に至る。博士 (工学). 進 化型ファジィシステム, 多目的知識獲得, 進 化型多目的最適化などの研究に従事.

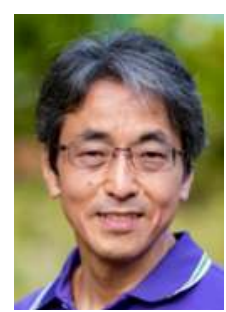

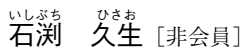

1985 年京都大学工学部機械系精密工学科卒 業. 1987 年同大学大学院工学研究科修士課程 精密工学専攻修了. 同年大阪府立大学工学部 助手, 1993 年同講師, 1994 年同助教授, 1999 年同教授. 2017 年南方科技大学計算機科学工 学科講座教授, 現在に至る。博士 (工学). 進 化型多目的最適化, ファジィ識別システム, ファジイ遺伝的機械学習などの研究に従事. IEEE Fellow.

\author{
[問い合わせ先］ \\ ５599-8531 大阪府堺市中区学園町 1-1 \\ 大阪府立大学大学院工学研究科 \\ 増山 直輝 \\ TEL: 072-254-9198 \\ FAX: 072-254-9825 \\ E-mail: masuyama@cs.osakafu-u.ac.jp
}




\section{Michigan-Style Fuzzy Genetics-Based Machine Learning for Class Imbalance Data}

by

Akihiro NISHIHARA, Naoki MASUYAMA, Yusuke NOJIMA, and Hisao ISHIBUCHI

\section{Abstract:}

Recently, interpretability of classifiers has been actively discussed in some real-world applications like medical and financial fields. Michigan-type Fuzzy Genetics-based Machine Learning (FGBML) is one of the most-well known methods for generating fuzzy classifiers with high interpretability. However, many real-world classification problems require high classification performance of a specific class which is less frequent than the others. For those problems, fuzzy classifiers generated by FGBML often have low classification performance for minority classes. Therefore, in this study, we extend FGBML for minority classes by applying the following four operations to the conventional Michigan-type FGBML: i) weighting the rule evaluation function by the number of patterns for each class, ii) changing the rule set evaluation function to the harmonic mean of the classification accuracy of each class, iii) selecting the base pattern in the heuristic rule generation based on the classification accuracy of each class, and iv) weighting the consequent part of each rule by the ratio of the number of the patterns between classes. Through computational experiment, we examine the effect of each change on the classification performance and show that the proposed method generates a fuzzy classifier with better classification performance than the conventional FGBML with SMOTE.

Keywords: fuzzy classifier, genetics-based machine learning, imbalance dataset

Contact Address: Naoki MASUYAMA

Osaka Prefecture University

1-1 Gakuen-cho, Naka-ku, Sakai, Osaka 599-8531, Japan

TEL: +81-72-254-9198

FAX: +81-72-254-9825

E-mail: masuyama@cs.osakafu-u.ac.jp 